\title{
Dios ante el abismo. La filosofia de la revelación de Schelling como Bildungsroman del espíritu
}

\author{
Jaime Llorente Cardo \\ "IES C. de Calatrava" (Ciudad Real, España)
}

Resumen: El propósito del presente estudio es reconstruir el modo en el que la filosofia tardia de Schelling, aquella representada por su reflexión acerca de la mitología y los fundamentos racionales de la revelación, describe la triple escisión del Absoluto en potencias diversas que tiene lugar con el ingreso de Dios en la temporalidad y el devenir. El proceso que da lugar a esta fragmentación de lo divino es interpretado como un "relato de formación" paralelo a la odisea que la conciencia finita experimenta como consecuencia de su constitutiva apertura al Ser. Palabras clave: Schelling; Bildungsroman; potencias; Ser imprepensable; Absoluto

Abstract: The aim of the present study is to rebuild the way in which Schelling's later philosophy -that which is represented by his reflection concerning mythology and rational foundations of revelation- describes the triple division of the Absolute in diverse potencies that takes place with the entry of God in temporality and becoming. The process that leads to such fragmentation of the divine is interpreted as a "formation novel" analogous to the odyssey that the finite conscience experiences as a result of its constituent openness to Being.

Key words: Schelling; Bildungsroman; Potencies; Unprethinkable Being; Absolute 
I. Del monoteísmo del espiritu al politeísmo de las potencias: los presupuestos de la filosofia positiva

La referencia a la idea de un "Dios en devenir" (Gott im Werden) resulta casi un lugar común a la hora de abordar los presupuestos "onto-teológicos" presentes en la Spätphilosophie o "filosofia tardia" de Schelling. Esta noción vendría a introducir un marcado sesgo de dinamismo y movimiento -no exento de padecimiento y participación en la negatividad en general- en el seno de la concepción spinoziana de lo Absoluto. De esta concepción definida por la clausurada y perfecta identidad constitutiva del modo de existencia propio de la substantia infinita sive Deus ${ }^{1}$ participaba con entusiasmo el propio Schelling en el llamado "período de la filosofia de la identidad" (1801-1804). No obstante, en 1803, al comienzo de la octava de sus Vorlesungen über die Methode des akademischen Studiums, Schelling ya declara lo siguiente: "Alli donde lo infinito mismo puede devenir finito, puede volverse también pluralidad; el politeísmo es posible. Alli donde solo es expresado por lo finito, permanece necesariamente uno y no es posible el politeísmo en cuanto existir simultáneo de figuras divinas (Zugleichsein göttlicher Gestalten). Este surge merced a la sintesis de lo absoluto (Absolutheit) con la limitación (Begrenzung), de modo que en ella ni el carácter absoluto de la forma ni la limitación son eliminados (aufgehoben). En una religión como el cristianismo, esto no puede ser tomado de la naturaleza, ya que no comprende lo finito en general como símbolo de lo infinito y en un sentido independiente (in unabhängiger Bedeutung). Solo puede ser tomado entonces de aquello que cae en el tiempo, es decir, de la historia"2. Un año más tarde, en el escrito Philosophie und Religion, Schelling niega explícitamente la existencia misma de este hipotético "tránsito" desde lo absoluto a lo finito que habría de posibilitar la fusión sintética entre infinitud y determinación.

1 En este sentido, en referencia a la fórmula "spinozismo de la fisica" mediante la cual Schelling define su Naturphilosophie, aclara Vicente Serrano: "la diferencia fundamental frente a Spinoza está justamente en el carácter dinámico de la infinitud, es decir, la diferencia está justamente en el modelo de la autoconciencia que hunde sus raices en los elementos fichteanos de Schelling y que es trasladado al punto de vista del objeto" (Serrano, V., Absoluto y conciencia. Una introducción a Schelling, Madrid: Plaza y Valdés, 2008, p. 218).

2 Schelling, F.W.J., Sämmtliche Werke, Stuttgart: Cotta, 1856-1861, v. V, p. 288. En adelante, citaremos esta edición como SW, seguido de número de volumen y página. Todas las traducciones, salvo indicación expresa en sentido contrario, son del autor. 


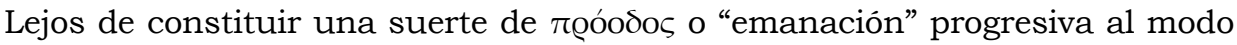
neoplatónico ${ }^{3}$, la "caída" (Abfall) de lo incondicionado en la finitud que "salva" la infinita distancia entre ambos, únicamente resulta concebible en términos de ruptura: de discontinuidad radical que acontece de modo instantáneo y no como resultado de un pro-cessus: "de lo absoluto a lo real no hay tránsito continuo (stetigen Uebergang) alguno, el origen del mundo sensible solo es pensable como una perfecta ruptura de la absolutidad (vollkommenes Abbrechen von der Absolutheit), a través de un salto (Sprung)"4.

El politeísmo, esto es, la fragmentación tripartita de la originaria unicidad

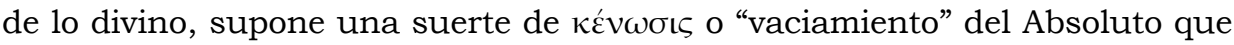
implica inevitablemente su ingreso en el flujo de la temporalidad, su participación en el proceso general del devenir ${ }^{5}$. La sintesis entre la infinitud propia del Absoluto y la finitud representada por lo determinado acontece solamente al cabo de un periplo temporal en el cual la odisea del espiritu divino coincide acaso con la propia de la consciencia finita (es decir, humana), en la medida en que ambas recalan en los mismos hitos: aquellos que jalonan el itinerario recorrido por la subjetividad en pos de lo infinito e incondicionado ${ }^{6}$. Tal coincidencia merced a la cual los itinerarios propios de las consciencias humana y divina van de consuno, es justificada por el propio pensador de Leonberg cuando, en referencia al concepto de "intuición intelectual", indica "que se llama

\footnotetext{
3 Sobre este aspecto, véase: Beierwaltes, W., "El neoplatonismo de Schelling", en: Anuario filosófico, v. XXX, 67 (2000), pp. 395-442.

4 SW, v. VI, p. 38.

5 Esta es la razón por la cual, en un artículo publicado en 1802 en el Kritisches Journal der Philosophie y cuya autoria es atribuida tanto a Schelling como a Hegel, puede leerse lo siguiente: "Haremos observar que nos resulta imposible pensar la religión, en cuanto tal, al margen de toda relación histórica... El germen del cristianismo fue el sentimiento de una división (Entzweiung) entre Dios y el mundo; su camino (Richtung) fue la reconciliación con Dios, no a través de una elevación (Erhebung) de la finitud a la infinitud, sino a través de una conversión en finito de lo infinito (Endlichwerdung des Unendlichen), a través del devenir hombre por parte de Dios... Podemos llamar misticismo en general a este sentido orientado hacia la intuición de lo infinito en lo finito. El misticismo es el modo de intuición demandado como necesario por el más íntimo espíritu del cristianismo" (Schelling, F.W.J., "Über das Verhältnis der Naturphilosophie zur Philosophie überhaupt", en: SW, v. V, pp. 117-118).

6 En su más reciente obra acerca del pensamiento de Schelling, Jean-François Courtine resume agudamente este esencial nexo entre revelación, historicidad del Absoluto y odisea de la consciencia humana: "Para Schelling, como hemos visto, la idea de revelación implica no solo la temporalidad y la historicidad, sino además, y sobre todo, el antagonismo de las fuerzas. Desde las Investigaciones, y más aun en las Conferencias de Stuttgart, Schelling subraya que, para que haya revelación, es necesario que el fondo suscite lo contrario del amor o de la voluntad universal, a saber: la propiedad (Eigenheit), el ser-propio, el ser. Así, aquello que se juega desde el comienzo en el plan teo-cosmogónico anterior al hombre, se repite y se dramatiza en él, que es la cima de la creación" (Courtine, J.-F., Schelling entre temps et éternité. Histoire et préhistoire de la conscience, Paris: Vrin, 2012, p. 45).
} 
intuición solo porque la esencia del alma, que es una y la misma cosa con el Absoluto, no puede tener con este otra relación sino la inmediata (unmittelbares)"7. Esta paralela "odisea de la conciencia" a la que se refiere certeramente Jankélévitch en su clásico estudio ${ }^{8}$, puede ser contemplada como la crónica de una epopeya de la autoconsciencia en la cual, de modo análogo a lo que sucede en el contexto de las "novelas de formación" clásicas (el Wilhelm Meister de Goethe o Heinrich von Ofterdingen de Novalis), la "esencia" final del protagonista se muestra como producto de los avatares padecidos a través del periplo diacrónicamente recorrido durante su "existencia" concreta, y sobre todo como resultado de su confrontación con las resistencias vitales surgidas a lo largo de su peregrinaje a través de la exterioridad ${ }^{9}$.Nos ocuparemos, pues, durante el presente estudio, de tratar de describir adecuadamente los jalones que pueblan la Bildungsroman constituida por la narración schellingniana de la "historia del Absoluto", manteniendo permanentemente la mirada sobre las conexiones que tal peripecia del espiritu universal mantiene con la particular epopeya del espíritu finito en su apertura a la exterioridad marcada por lo mundano. Se trata, por tanto, de rastrear el paralelismo existente entre el "calvario ontológico" experimentado -según el último Schelling- por la subjetividad divina, y el hipotéticamente análogo proceso "epistemológico" padecido por la consciencia humana en el marco de su relación con ese fondo indeterminado de la existencia radicalmente previo a toda reflexión y pensamiento al que el propio Schelling se refiere mediante la expresión "Ser imprepensable" (unvordenkliche Seyn) ${ }^{10}$. Este Ser originario coincide con la esencia, en un primer momento absolutamente idéntica a sí misma, del

7 SW, v. VI, p. 23.

8 "L’univers n'est pas un système; mais une histoire. Voilà pourquoi il existe une philosophie de la Mythologie et de la Révélation. Le philosophe n`aurait rien à dire sur 1`histoire religieuse de la conscience si l'exploration du devenir humain n’impliquait la découverte d’un devenir plus profond au centre même de l’Absolu; 1`histoire de l'erreur païenne n'aurait aucun intérêt si nous ne savions qu'elle reproduit dans le monde une grande aventure métaphysique; en sorte que l'évolution humaine fait toujours pendant à l'évolution divine, et que les deux perspectives sont inséparables" (Jankélévitch, V., L'odyssée de la conscience dans la dernière philosophie de Schelling, Paris: L'Harmattan, 2005, p. 3).

9 En palabras de Ana Carrasco Conde: "El absoluto presentado por Schelling es un absoluto en devenir, que se manifiesta temporal e históricamente a través de la gesta por ser él mismo... El mundo no es un mecanismo geométricamente concebido. La creación ha de ser entendida como parte del proceso por el que Dios va tomando conciencia de sí desde la inconsciencia" (Carrasco Conde, A., La limpidez del mal. El mal y la historia en la filosofia de F.W.J. Schelling, Madrid: Plaza y Valdés, 2013, pp. 95-97).

${ }^{10}$ Schelling, F.W.J., “Andere Deduktion der Principien der positiven Philosophie", en: SW, v. XIV, p. 337.

ARETÉ Revista de Filosofía, vol. XXVIII, N², 2016 / ISSN 1016-913X 
Absoluto, pero también, siguiendo el paralelismo ya indicado, admite ser parangonada con el Ser que -en el sentido apuntado por la "diferencia ontológica" heideggeriana- hace aparecer a los entes finitos y que constituye el correlato inmediato de la percepción humana. Schelling alude a este Ser radicalmente distinto de los existentes concretos en múltiples pasajes de su obra diseminados a través de la totalidad de las fases o etapas que la configuran. Así, en la primera versión (Urfassung) de la proyectada obra inconclusa Die Weltalter (1811), Schelling escribe: "las cosas no se muestran como acabadas por el mero hecho de pertenecer necesariamente a su simple existencia, sino que hay otra cosa en torno a ellas o en ellas que es lo único que les confiere todo el brillo y todo el esplendor de la vida: algo superfluo juega, por así decirlo, en torno a ellas, por lo cual ellas son bañadas e inundadas, un Ser (Seyn) ciertamente inaprehensible, pero que no pasa desapercibido"11. Se trata, por tanto, de un Ser no susceptible de ser captado mediante la mera intuición sensible ni tampoco disponible para el pensamiento reflexivo y conceptual, pero sí accesible de modo inmediato para la intuición intelectual. Si consideramos de modo provisional a la intuición como una "facultad del alma", no resulta sorprendente esta postulada continuidad entre intuición y aprehensión de lo incondicionado, puesto que, dado el parentesco apuntado por Schelling en 1804 entre la esencia del alma y el Absoluto, este únicamente resulta perceptible en virtud de un acto de captación instantánea. ¿Y no es precisamente la intuición aquella facultad vinculada de forma preeminente a la noción misma de inmediatez perceptiva? ${ }^{12}$. La relación establecida entre Ser y ente, así como la existente entre intuición intelectual y Ser incondicionado, guarda una estrecha analogía con la "diferencia ontológica" entre Sein y Seiendes que constituye el núcleo de la ontología heideggeriana (o más bien sucede a la inversa) y con el modo en que Heidegger establece un nexo esencial de continuidad entre el "darse" (sich geben) del Ser distinto de los entes y la percepción (Wahrnehmung,

\footnotetext{
${ }^{11}$ Schelling, F.W.J., Die Weltalter. Fragmente. In der Urfassungen von 1811 und 1813 (SW, Nachlassband), Múnich: Beck, 1966, p. 32.

${ }^{12}$ Tal cosa sucede, por supuesto, solo en referencia a la intuición no sensible, que por ello tiene como correlato no un "objeto" particular, sino un elemento igualmente "no objetivo", es decir, incondicionado, simple e indeterminado (el puro Ser). Ya en el Erster Entwurf eines Systems der Naturphilosophie de 1799, Schelling aclara, en referencia a la correcta conceptualización de "lo incondicionado", que ello "no puede en general ser buscado en alguna 'cosa' individual, ni en algo de lo que se pueda decir que 'es'. Porque el 'qué es' admite solo parte del Ser, y es solamente una forma individual o modo del Ser (Art des Seyns). A la inversa, nunca puede decirse de lo incondicionado que 'es', puesto que es el Ser mismo, el cual no se muestra (darsellt) totalmente en ningún producto finito, y todo lo individual es, en cierto modo, solamente una particular expresión suya" (SW, v. III, p. 11).
} 
Seinsverständnis) humana ${ }^{13}$. La apertura de la intuición finita a este Ser refractario a toda tentativa de conceptualización y reducción al discurso reflexivo (esto es, a su modo, "imprepensable") constituye, pues, el origen de una Bildungsroman a través de la cual la conciencia finita aprende progresivamente a reconocer tanto lo absoluto como a sí misma (o quizá incluso a reconocerse a sí misma en lo absoluto) ${ }^{14}$. Esta epopeya de la personalidad finita expuesta al puro Ser indeterminado constituye acaso una derivación de aquella otra acaecida en el propio seno de la conciencia del Absoluto merced a la cual, tras la "ruptura de la absoluteidad" y el "salto" que dan lugar a la aparición del mundo finito, existe toda realidad determinada (incluida la propia conciencia individual humana). La previa y paralela Bildungsroman del espíritu absoluto comienza, según Schelling, con una escisión originariamente acontecida en lo más profundo de la consciencia divina; un cisma ontológico que fragmenta la original unicidad de Dios -el fundamento mismo del "monoteísmo del espíritu"dando así lugar a su segmentación en múltiples "potencias". A partir de aquí, tal "sintesis entre lo absoluto y la limitación" en la cual ninguno de los dos extremos es eliminado, permite la coexistencia de "múltiples figuras divinas" postulada por el Schelling de las Vorlesungen de 1803. Más allá de la "filosofia puramente racional" hegeliana como del "salto irracional a la fe" preconizado por Jacobi, la "filosofia positiva" desarrollada por Schelling en sus lecciones sobre "Filosofia de la Revelación" trata de pensar el simple hecho (blosse Tatsache) de la facticidad de Dios, del puro Ser de lo divino, de forma

13 "Los griegos han determinado en primer término el modo de acceso a lo presente en el sentido del encontrar presente (Vorfinden) en la intuición”, en el sentido de la recepción intuitiva, en el

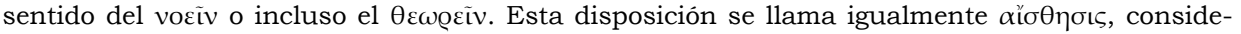
ración estética en sentido propio, aquel en el cual Kant emplea aún el término estética, pura recepción considerativa del ente subsistente. Es gracias a esta actitud puramente intuitiva -que nunca es más que una modificación del ver en el sentido de la circunspección, del comportamiento productivo- como la efectividad de lo efectivo se desvela" (Heidegger, M., Grundprobleme der Phänomenologie, GA) v. XXIV, Fráncfort d.M.: Vittorio Klostermann, 1975, p. 154).

${ }^{14}$ Conviene, sin embargo, no perder de vista que en el pensamiento del último Schelling el orden de preeminencia habitual entre Ser y ente (que privilegia al primero sobre el segundo) se presenta invertido. En este sentido, apunta Félix Duque: "Desde una cierta lectura que conecta a la Escolástica con Heidegger, solemos entender por el Ser (el esse) un principio más elevado que el Ente (que, al fin, se limitaria a ser 'partícipe' del actus essendi). Pero en Schelling la dignidad es justamente inversa; el 'ser' es un principio opaco: lo determinable, la 'materia prima' de la que surge Dios. En cambio, el Ente es el Existente, Dios sensu eminenti” (Duque, F., Historia de la Filosofia moderna. La era de la crítica, Madrid: Akal, 1998, pp. 913-914, nota 2116). Considérese a este respecto, y a modo de ejemplo altamente ilustrativo, el siguiente pasaje: "Poner el Ser como lo primero quiere decir ponerlo sin el ente. Pero, ¿qué es el Ser sin el ente? El ente es lo primero, el Ser solamente lo segundo, puesto que es impensable por sí solo" (Schelling, F.W.J., "Vorrede zu einer philosophischen Schrift des Herrn Victor Cousin", en: SW, v. X, p. 215). 
"diacrónica", esto es, en cierto sentido, "histórica"15. Este procedimiento "metódico" no implica, sin embargo, mediatizar a través de conceptos discursivos aquello que -como se apuntó- solamente se da de forma inmediata, como sí sucede en el caso de la "filosofia negativa": "La filosofia anterior creía poder mediatizar la relación entre Dios y el mundo con puros conceptos universales del entendimiento"16. Muy al contrario, el camino abierto involuntariamente por Kant y consolidado por la distinción fichteana entre "Yo" y "no-Yo" se orienta en la dirección conducente a la recuperación de los principios efectivos del Ser. Tal acceso renovado a los primeros principios es consumado, según Schelling, por su propia Naturphilosophie en la medida en que esta pone de manifiesto el hecho de que, lejos de constituir categorias reciprocamente excluyentes, lo objetivo y lo subjetivo se dan de modo simultáneo en la totalidad de las regiones de lo real: "es precisamente así como sujeto y objeto fueron entonces realmente

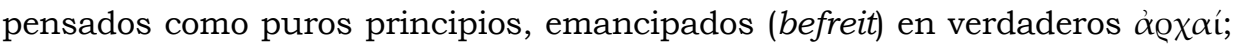
es de esta forma como los principios inmediatos del Ser fueron hallados de nuevo, y por ello le fue posible también a la filosofia salir del concepto subjetivo puro con cuya ayuda intentaba hasta entonces mediatizarlo todo. Así pudo [la filosofia] acoger en sí (in sich aufzuhehmen) el mundo objetivo, y ahí tuvo lugar la mayor transformación que se ha producido en filosofia desde Descartes"17.

Esta mutación merced a la cual "el mundo objetivo en toda su amplitud deviene contenido de la filosofia", marca precisamente el origen del proceso -como todo pro-cessus, necesariamente sucesivo y mediado- que habrá de conducir "desde las profundidades de la naturaleza hasta las más elevadas cumbres del mundo espiritual"18, culminando, en su última fase, con el acceso a la causa absoluta (absoluten Ursache). Este "proceso continuo" (fortgehender Process) de la consciencia cuyos grados (Stufen) conducen paulatinamente hacia una constante intensificación (fortwährenden Steigerung) de lo subjetivo, es justamente aquello que nosotros designamos mediante la fórmula

\footnotetext{
15 No obstante, según la conocida tesis de Walter Schulz, tal oposición no sería absolutamente radical, sino susceptible de ser disuelta en una unidad superior: "Ambas filosofias [positiva y negativa] no son incardinadas en dominios definidos y autónomos, sino que constituyen partes de un único movimiento merced al cual la razón mediatiza cognoscitivamente su propio contenido: la pura actividad" (Schulz, W., Die Vollendung des Deutschen Idealismus in der Spätphilosophie Schellings, Stuttgart: Kohlhammer, 1955, p. 188). Sobre esta cuestión, puede consultarse: Augusto, R., "La evolución intelectual del último Schelling: filosofia negativa y filosofia positiva", en: Anuario filosófico, v. XLII, 96 (2009), pp. 577-600.

16 Schelling, F.W.J., "Der Philosophie der Offenbarung. Erster Theil", en: SW, v. XIII, p. 245.

17 Ibid.

18 Ibid., p. 246.
} 
"Bildungsroman del espíritu", relato que, como tal, ha de mostrar necesariamente un carácter gradual y sucesivo, pero en el cual, paradójicamente, el comienzo y el final de la trama narrativa coinciden. La filosofia positiva, en tanto que negación del pensar "puramente racional", supone a la vez una "demostración del Absoluto" y una radical destrucción de la universalidad del principium rationis. Tal simultaneidad -en principio racionalmente impensable- se torna factible desde el momento en el que Schelling, tras haber descrito el "proceso histórico" del Absoluto como un fenómeno de intensificación progresiva de la subjetividad, describe consecuentemente su naturaleza o "esencia" del siguiente modo: "Hay, pues, Un sujeto que es tres, y la unidad que es pensada en este sujeto no puede ser ella misma sino espiritual (geistige), es decir, que él mismo no puede ser sino espiritu"19. Ahora bien, ese "hay" (es ist) que encabeza la frase remite inequívocamente, no a la "esencia" del Absoluto, sino a su existencia efectiva: al puro hecho de su ser.

Schelling es consciente de que la necesidad de demostrar la existencia del Absoluto (sea este de esencia "espiritual" o de cualquier otra) implica el riesgo de que todo el desarrollo de la filosofia positiva se torne meramente "hipotético". Sobre el Absoluto espiritual schellinguiano gravita la sombra del principio de razón suficiente (o Satz von Grund) que constituía precisamente la raíz misma de la Reinrationalen Philosophie tradicional: "omne ens habet rationem", "nihil est sine ratione". Así pues, si el Absoluto -en cuanto "es" un ente- admite en general "ser demostrado", esto es, derivado a partir de un principio anterior, deja inmediatamente de constituir tal Absoluto. Por el contrario, en caso de postular que al Absoluto no le conviene la aplicación del "principio de razón", se estaría hablando de un ser que non habet rationem, es decir, carente de fundamento (Grund) y por tanto indemostrable, con lo cual el núcleo mismo de la "filosofia positiva" reposaria sobre una simple hipótesis no susceptible de prueba (Beweis) alguna. Reaparece aquí, en último término, el problema de la relación entre lo mediatizado por conceptos del entendimiento (no otra cosa es en general "algo demostrado") y lo dado de forma inmediata a la pura intuición. Schelling resuelve esta aporía fundacional del único modo posible: situando el origen y la fuente de toda racionalidad en el existir originario del espíritu absoluto, postulándola como simultánea a este existir e identificándola radicalmente con él. De este modo, "razón" y "ser del Absoluto" se presentarían como instancias co-originarias: "La efectividad primera (erste Wirklichkeit) nos es dada en este

19 Ibid., p. 247.

ARETÉ Revista de Filosofía, vol. XXVIII, N² 2, 2016 / ISSN 1016-913X 
espiritu del cual puede ciertamente decirse: si hay un ser racional o libremente puesto (ambas cosas son lo mismo), entonces tal espíritu debe existir; pero no hemos de ningún modo aprehendido la absoluta necesidad de este, tampoco la hemos en absoluto deducido (abgeleitet), de algún modo, de la razón"20. La existencia de un ser racional finito presupone ya con necesidad el previo existir del espíritu racional absoluto, sin que por ello sea requerido un fundamento (una demostración o Beweisung) racional de este: "el ser racional y la razón misma existen solo porque este espíritu existe, por este motivo precisamente solo podemos decir que él Es, lo cual equivale a decir que es sin fundamento (er grundlos ist), o que simplemente Es porque Es (Ist, weil er Ist), sin ninguna necesidad que le preceda" 21 . En tanto que existe de forma absolutamente incondicionada, el espíritu perfecto encarna él mismo la causa, el fundamento o la raison d'être misma de toda razón posible ${ }^{22}$. Difícilmente, pues, puede el "principio de razón suficiente" requerir el porqué o la razón de la existencia del Absoluto, dado que esta constituye precisamente la condición de posibilidad de ese mismo principio y de toda la racionalidad que se funda sobre él en general: su presupuesto necesario. Esta peculiar variante de hýsteron próteron que invierte el habitual orden de prioridad entre la demonstratio y lo demonstrandum es justamente el instrumento metódico que Schelling utiliza para lograr un doble fin. En primer lugar, asestar un golpe decisivo en la línea de flotación misma de la "filosofia puramente racional" o "negativa". En efecto, desde el momento en que la razón es depuesta del trono de los principios y sustituida por la simple facticidad ohne Grund (sin fundamento) del Absoluto, la universal tirania ejercida por el Satz von Grund, (el "principio de razón" o "proposición del fundamento") se diluye; o mejor dicho, deviene algo derivado y subsidiario con respecto a la radical originariedad del "espíritu perfecto" que la antecede: "Así es destruido el fundamento de todo racionalismo filosófico, es decir, de todo sistema que eleva la razón a principio"23. En segundo lugar, la mencionada inversión de los términos demostrativos permite a Schelling, una vez demolidos los cimientos de la "filosofia negativa", justificar y fundamentar su propia "filosofia positiva",

\footnotetext{
20 Ibid.

21 Ibid.

22 "El fundamento o, dicho más correctamente, la causa de la razón es, pues, más bien dada desde el comienzo ella misma en este espíritu perfecto (vollkommenen Geist). No es la razón la que es causa del espíritu perfecto, sino que no hay razón más que porque este existe... Solamente porque existe un espíritu perfecto, existe o hay una razón. Pero este espíritu mismo existe sin fundamento, absolutamente (schlechthin), porque él Es" (Ibid., p. 248).

23 Ibid.
} 
entendiendo por tal aquel pensamiento que reconoce la absoluta prioridad y antecedencia del Absoluto con respecto a toda posible instancia hipotéticamente anterior a él desde el punto de vista de la existencia ${ }^{24}$. La "inmunidad" al poder del principium rationis de la que goza el Absoluto no significa que este sea "totalmente indemostrable (unbeweisbar)", bien al contrario: "toda la filosofia (positiva) no es precisamente otra cosa sino la demostración (Erweis) de este espíritu absoluto. Él no tiene ningún prius, sino que es él mismo el prius absoluto, y por ello no se puede llegar a él a partir de ningún otro prius"25. Esto quiere decir que todos los instrumentos conceptuales que nosotros podamos utilizar para lograr un efectivo acercamiento y acceso al Absoluto, así como todas las "fases" o "escalones" (Schelling habla explicitamente al respecto de Stufen y Sprossen) que nuestra conciencia haya de recorrer durante el itinerario tendente a su "demostración", no mediatizan realmente la original existencia del "espíritu perfecto". La radical originariedad que la filosofia positiva schellingniana concede a este (su estatus de absolute Prius emancipado del principio de razón) impide desde el comienzo que instancias tan inevitablemente ligadas al concepto de "mediación sucesiva" como "proceso", "fase", "escalón", "prueba" o la propia noción de "método demostrativo" se sitúen, en cierto modo, como anteriores al propio Absoluto, poniendo a este en evidencia como algo derivado de principios anteriores, es decir, como mediatizado en cierto modo por la racionalidad humana ${ }^{26}$. Nuevamente

\footnotetext{
${ }^{24}$ En este sentido, apunta certeramente Félix Duque: “Desde luego el 'hecho' (Dass, quod) de la Existencia es inaccesible a la razón: ¡pero para ello es necesario que sea la misma razón -mutatis mutandis, como en Kant- la que haga la experiencia negativa de sus propios límites, en vez de hacer perezosa o asustadiza dejación de sus derechos y abandonar a los hombres a una creencia injustificada e injustificable! Por otra parte, una vez aceptada la experiencia de la Revelación la filosofia (una filosofia positiva, no puramente 'racionalista') puede y debe explorar racionalmente esa experiencia, haciendo inteligible y aceptable para el hombre... la esencia o quid de la Divinidad... Entre el racionalismo y el fideísmo irracional hay un tertium quid. Tal es el gran descubrimiento de Schelling: la por él ulteriormente denominada filosofia positiva" (Duque, F., o.c., pp. 908-909, nota 2103).

${ }_{25}$ SW, v. XIII, p. 248.

${ }^{26}$ Se trata, pues, de la misma originariedad refractaria toda demanda de demostración que el joven Schelling -bajo la influencia fichteana- reivindicaba para el Yo absoluto y su incondicionada libertad: “¿Reclamáis la conciencia de esta libertad? ¿Pero habéis pensado solamente en el hecho de que es únicamente gracias a esta libertad que toda conciencia es para ti posible y que la condición (Bedingung) no puede jamás ser contenida en lo condicionado (Bedingten)? ¿Habéis pensado en general en el hecho de que el Yo, desde el momento en el que es traido (vorkommt) a la conciencia, no es ya puro Yo absoluto; que para el Yo absoluto no podría haber en ninguna parte objeto alguno y, que, por tanto, mucho menos aun puede convertirse él mismo en objeto? La conciencia de sí presupone el peligro de perder el Yo... Pero esta aspiración (Streben) del Yo empírico, así como la conciencia resultante de él, no serian posibles ellas mismas sin la libertad del Yo absoluto" (Schelling, F.W.J., "Vom Ich als Prinzip der Philosophie oder über das Unbedingte im menschlichen Wissen", en: SW, v. I, pp. 180-181). Es aplicable aquí aquello que Vicente Serrano indica refiriéndose a las Philosophische Briefe de 1795: "La pregunta kantiana ha sido transfor-
} 
en oposición a la Reinrationalen Philosophie, Schelling invierte también aquí la tradicional forma de contemplar el sentido progresivo propio de todo método de demostración. Cuando la razón finita se sirve de los "principios del Ser" (como Schelling los llama), es decir, de los mencionados "escalones" mediadores, a fin de aproximarse gradualmente al espíritu absoluto, es necesario tener en cuenta que estos "eran tales solamente para nosotros (für uns), y también solo con un fin propedéutico (didáctico), pero nos ha sido necesario asimismo tomar conciencia de que objetivamente considerada, es decir, desde el punto de vista de este espíritu mismo, la relación se invierte y estos principios son más bien la consecuencia (Folge), el posterius con respecto a él"27. Otro tanto podría decirse en referencia a las etapas sucesivas y fases progresivas que aparentemente "median" el periplo de la consciencia absoluta (su Bildungsroman) a través de la temporalidad y la finitud, las cuales, como acaba de verse, mantienen un estrecho paralelismo ontológico y gnoseológico con el movimiento propio de la racionalidad humana. La precedente exposición de los presupuestos fundamentales de la filosofia positiva de Schelling ha contribuido, pues, a localizar y perfilar dos "relatos de formación" tan infinitamente distantes como equivalentes en última instancia: los protagonizados por la consciencia absoluta y por el sujeto finito. En los apartados siguientes, tomaremos como hilo conductor del discurso el análisis e interpretación de esta doble Bildungsroman cuya clave radica en las diferentes consecuencias que supone para la subjetividad humana y para la divina su común participación en el darse del puro Ser indeterminado distinto de los existentes concretos.

\section{Entre el Ser imprepensable y la trinidad potencial: la Bildungsroman del} Absoluto

Dada la absoluta unidad y originariedad de Dios en tanto que se muestra, como hemos visto, en términos de prius absoluto, la cuestión decisiva que ha de resolver seguidamente la filosofia positiva es aquella planteada por el modo en el que resulta posible que algo exista en general praeter Deum, es

mada por una pregunta claramente ontológica. La pregunta sobre las condiciones de posibilidad de la experiencia se ha convertido en la pregunta de cómo es posible el abandono del Absoluto, del que la experiencia en cuanto finitud es el resultado" (Serrano, V., o.c., p. 161).

${ }^{27} \mathrm{SW}, \mathrm{v}$. XIII, p. 248. Es por ello que, como conclusión, "el espíritu absoluto puede verdaderamente, por tanto, ser demostrado (bewiesen) por estos principios, pero no puede ser demostrado por ellos como por su prius (als durch sein prius), sino que puede serlo únicamente como por su posterius, es decir, que no puede en general ser demostrado más que a posterior" (Ibid., pp. 248-249). 
decir, fuera de Dios. Desde la perspectiva del Schelling maduro, el verdadero monoteísmo, el "monoteísmo conceptual" (Monotheismus im Begriff), surge solamente cuando una auténtica pluralidad es situada en el seno del Espíritu Absoluto. En abierta oposición a la tesis central propia del teísmo "ortodoxo", el monoteísmo postulado por la filosofia positiva adopta como presupuesto último el "hecho" de que Dios no existe simplemente bañado por el éter de su pura unicidad, sino que esta unidad constitutivamente suya ha de ser concebida no en términos negativos (como mera ausencia de pluralidad), sino de forma afirmativa ${ }^{28}$. Schelling comprende tal unidad afirmativa del espíritu absoluto del siguiente modo: "La afirmación de la unicidad (Einzigkeit) no es afirmativa más que si una multiplicidad (Mehrheit) es puesta desde el principio en una esencia, y si la unidad (Einheit) de la esencia es afirmada como tal... La condición de la afirmación de una efectiva unidad de Dios es, por tanto, que desde el principio sea puesta en él una pluralidad"29. La afirmación "hay un solo Dios" (es sey nur Ein Gott) solamente es posible en sentido propio en la medida en que Dios es pensado de algún modo como "plural", sin por ello incurrir en la postura politeísta tradicional que extraería de esta afirmación la tesis de la existencia de múltiples dioses. Según Schelling, esta paradójica relación entre lo uno y lo múltiple en el interior de la conciencia del Absoluto es la única que constituye verdaderamente una afirmación positiva de la unicidad divina ${ }^{30}$. Ello se debe a que cuando el monoteísmo tradicional cree preservar

\footnotetext{
${ }^{28}$ Para una visión general acerca de esta cuestión, véase: Fuhrmans, H., "Der Gottesbegriff der Schellingsche positiven Philosophie", en: Koktanek, A.M. (ed.), Schelling-Studien. Festgabe für M. Schröter zum 85. Geburtstag, Múnich/Viena: R. Oldenbourg, 1965, pp. 9-47.

29 SW, v. XIII, p. 282. En sus lecciones de 1842 sobre "El monoteísmo", Schelling aclara la diferencia entre los conceptos de "teísmo" y "verdadero monoteísmo". Allí, partiendo de la proposición teológica tradicional según la cual "hay un Dios", declara: "se muestra con evidencia que esta proposición no implica el monoteísmo, sino un simple teísmo. Para explicar el contenido de la proposición hay un 'Dios', fuera del cual podria haber uno o muchos otros Dioses, pero hay solamente uno, la palabra teísmo bastaria sobradamente, y el compuesto 'monoteísmo' resultaría totalmente superfluo... Hubo un tiempo en el que el nombre de teísta no gozaba de favor. Decir de alguien que era teísta, suponía casi calificarlo de ateo, designarlo como alguien que afirma, no al verdadero Dios, sino en su lugar a un mero fantasma o simulacrum del verdadero Dios... Pero ahora, una vez desaparecidos de nuestra mirada el peligro e incluso toda posibilidad de poliatría (Vielgötterei), nada impide por fin hacer desaparecer expresamente el monoteísmo en tanto que concepto particular... y a la expresión tautológica y en el fondo solamente pleonástica 'el Dios único' disolverse (sich auflöse) en el concepto superior y más universal (allgemeineren) de Dios, el cual no precisa de añadido alguno (keines Zusatzes bedarf)" (Schelling, F.W.J., "Philosophie der Mythologie. Erstes Buch: Der Monotheismus" en: SW, v. XII, pp. 21-23).

30 En referencia a la concepción schellingniana de la identidad divina, Miklos Vetö aclara: "Es gracias a esta impasibilidad-invulnerabilidad como Dios puede optar por la creación, asumir la extraordinaria aventura de la Encarnación. La kénosis y la unicidad se encuentran en relación orgánica. Lo único es reconocido por su aptitud para existir en los contrarios, para conservar su
} 
la estricta unidad de Dios mediante la afirmación de que "él es uno", lo que hace realmente es proferir de forma tácita el enunciado negativo según el cual Dios "no es múltiple". Así pues, tal monoteísmo afirma realmente lo contrario de lo que pretende. Su concepción acerca de la unidad absoluta de la esencia divina redunda, de modo paradójico, en la inversa posición conforme a la cual "es más bien la pluralidad la que es afirmada inmediatamente, mientras que la unidad en cuanto tal no es afirmada más que de modo mediado y únicamente a través de su oposición a esta pluralidad"31.

El designado por Schelling como "monoteísmo del dogma” sitúa, pues, de forma larvada e involuntaria, la pluralidad como una noción más originaria que la de unidad (y previa, por tanto, a ella) a la hora de fijar el atributo esencial del espíritu divino. El auténtico "monoteísmo del concepto" no puede contentarse con esta mera tesis negativa, sino que precisa de una doctrina de carácter afirmativo, esto es, "positiva". La auténtica expresión del monoteísmo en tanto que doctrina positiva acerca del Absoluto pasa, al decir de Schelling, por presuponer racionalmente un acto de atomización o fraccionamiento de la vacía e indirecta unidad de Dios afirmada por el "monoteísmo dogmático". Es aquí donde hacen su aparición en el marco de la filosofia de la revelación schellingniana los decisivos conceptos de "totalidad" (Allheit) y "proceso" (Process). Dios es totalidad (no estrictamente "unidad") en la medida en que el concepto de totalidad implica la fusión y conjunción de la unidad y la pluralidad ${ }^{32}$. La diferencia entre estas dos nociones deviene, cuando es proyectada al ámbito ontológico, tránsito: proceso conducente a la ex-presión del Absoluto "fuera de sí mismo", inicio de una Bildungsroman merced a la cual acontece la efectiva posición de algo praeter Deum: "Conforme a las figuras de su ser, Dios no es uno sino totalidad, y por tanto pluralidad (puesto que la totalidad no es sino una pluralidad cerrada, acabada). Pero esta pluralidad no surge como tal más que en la escisión de las potencias, es decir, en el proceso: pero es ahí también

identidad en su contrario. La kénosis es el descenso de Dios, su auto-abajamiento, su devenir menos que sí-mismo, su inmersión en el mundo" (Vetö, M., "L'unicité de Dieu selon Schelling", en: Courtine, J.-F. y J.-F. Marquet (eds.), Le dernier Schelling. Raison et positivité, París: Vrin, 1994, p. 99).

31 SW, v. XIII, p. 282.

${ }^{32}$ Ya en 1802, y con el característico sesgo panteísta propio del período de la "filosofía de la identidad", Schelling había apuntado que: "el absoluto, que es por sí mismo una unidad absoluta, absolutamente simple (schlechthin einfach), carente de toda pluralidad (Vielheit), se convierte en el fenómeno en una unidad absoluta de la pluralidad, en una totalidad clausurada (beschlossene), a la cual llamamos universo" (Schelling, F.W.J., "Bruno oder über das göttliche und natürliche Prinzip der Dinge", en: SW, v. IV, p. 312). 
donde la unidad surge como tal; Dios es, en efecto, aquel que está en el seno de las potencias, aquel que actúa y crea en ellas, y en cuanto tal él no es muchos sino uno, y es, pues, aquí que el monoteísmo (como doctrina) puede encontrar su expresión"33.

El fundamento de Dios en cuanto totalidad, esto es, de la unitas multiplex del Absoluto, reside en la doctrina schellingniana sobre las potencias. Si la condición de posibilidad de una auténtica afirmación de la unidad de Dios es que una cierta pluralidad sea presupuesta en él, esto solo es posible, desde la óptica schellingniana, gracias a la segmentación de aquella unidad en una triada de elementos "cosmogónicos" que, lejos de quebrarla, más bien la fundamentan y preservan ${ }^{34}$. Empleando una terminología que posteriormente alcanzará celebridad con Hegel y Sartre, Schelling propone un primer esbozo de la originaria tripartición de la esencia del Absoluto distinguiendo en su interior entre: "el espíritu que es en sí, el que es para sí y aquel que es para sí en el en sí”. Es de esta forma como Dios puede ser múltiple sin que ello implique la verdad del politeísmo. Estas tres "figuras" (Gestalten) se le presentan al propio espíritu absoluto como "otras tantas potencias de un ser por venir (künftigen Seyns)": como modos de ser aún simplemente potenciales, contenidos in nuce en su propia esencia, pero todavía no explicitados. Por esa razón el "espíritu viviente" no es definido por Schelling debido a su pura efectividad presente, como aquel que simplemente "es", sino como "aquel que será"35. Aquí es donde radica la entera concepción schellingniana acerca del "devenir de Dios", y es

\footnotetext{
${ }^{33}$ SW, v. XIII, p. 283.

${ }^{34}$ Sin embargo, en el mencionado diálogo Bruno, Schelling aún consideraba, en referencia al Absoluto como totalidad, que este: "no puede tampoco cambiar su forma interior (innerliche Gestalt); puesto que también toda transformación, perfeccionamiento o empeoramiento de las formas, existe solamente en el modo de considerar propio del individuo. Pero si pudiésemos contemplarlo como un Todo, mostraria a los ojos embriagados y fascinados un rostro siempre inmutablemente sereno (unveränderlich heiteres) e idéntico a sí mismo" (SW, v. IV, p. 314).

35 "Por todas partes, no hemos reconocido al espíritu más que como espíritu existente absolutamente en sí mismo, totalmente vuelto hacia el interior en dirección a sí mismo, acabado y perfecto en sí, espiritu que no tiene necesidad de nada fuera de sí. Por sí mismo, por su naturaleza, él es el Solitario (solitarius)... Hemos expuesto, pues, al espíritu como tal efectividad puramente presente (rein gegenwärtige), que no anuncia ningún porvenir, totalmente cerrada sobre sí. Pero también hemos explicado al mismo tiempo que en el espiritu está oculto el porvenir (das Zukünftige), aquello que será (das, was seyn wird). Nuestra próxima tarea es mostrar cómo ahora este porvenir se deja intuir desde el comienzo o surge como posible, y cómo en esta relación el espíritu aparece ahora también como libertad de ser... a saber: como libertad de existir fuera de sí, de exponerse fuera de sí, de poner un ser fuera de sí mismo... Como espíritu que no es ya simplemente libertad de no ser, que es también libertad de ser, entendiéndolo como tal espíritu, él no aparece simplemente como el espíritu perfecto, sino como el espíritu viviente (lebendige Geist), efectivamente como aquel que será (der, der seyn wird)" (SW, v. XIII, pp. 260-261).
} 
desde este prisma como resulta necesario considerarla. Así lo hace J.-F. Courtine cuando escribe: "esta elucidación de la libertad humana es la que constituye el verdadero hilo conductor de la filosofía positiva cuya característica principal es ser también una filosofia histórica, es decir, atenta a la temporalización en Dios. Un Dios histórico, es decir, un Dios que propiamente se temporaliza y entra en la historia, debe, en efecto, dejarse afectar por el devenir"36.

Schelling describe cada una de las potencias propias del "Absoluto en devenir" del siguiente modo: "La primera sería la potencia inmediata de otro ser, de un ser contingente, el poder-ser inmediato, el poder-ser de la primera potencia... La segunda sería el poder-ser de segundo rango, la tercera el poder-ser de tercer rango... No tenemos necesidad de decir de la primera que es el poder-ser inmediato, sino que nos basta con decir simplemente que ella es el poder-ser; y la serie de las potencias, tal como se presentan al Espíritu Absoluto y en él, es, pues, la siguiente: 1) el poder-ser (das Seynkönnende), 2) Aquello que tiene necesidad de ser (das Seynmüssende), 3) El deber ser (das Seynsollende). Con ello hemos comprendido... todas las archi-categorias del ser. Acaba de verse cómo aquello que en el Espíritu Absoluto era =Él mismo puede convertirse en potencias de un ser otro y por venir"37.

Nos interesa fundamentalmente la primera de estas potencias, en la medida en que la totalidad del proceso de "potencialización" del Absoluto tiene su origen en una inmediata y originaria intuición interna de la alteridad que acontece en el más profundo seno de la consciencia divina. En efecto, Dios "percibe" originalmente la posibilidad (el "poder-ser") del surgimiento en el interior de su esencia de algo "otro que sî"38. Este inicial atisbo de alteridad en la esfera de la "perfecta" unidad propia del Espíritu Absoluto es el auténtico germen de la disolución de su Voll-kommenheit, de su acabada y totalmente completa per-fectio, y a la vez, constituye el origen de su odisea cognoscitiva a través de la temporalidad exterior a él. Se trata de un rasgo decisivo en el contexto de la Potenzlehre (teoria de las potencias) schellingniana, dado que sitúa la negatividad, la no-identidad o la remisión a lo diferente y futuro (aún no existente), en las profundidades mismas de la compacta identidad

\footnotetext{
${ }^{36}$ Courtine, J.-F., Schelling entre temps et éternité...., p. 48.

37 SW, v. XIII, p. 267.

38 "Desde el momento en el cual el Padre percibe en las figuras propias de su ser la posibilidad de otro ser, o bien desde el momento en el que estas figuras se le muestran como potencias, es decir, desde la eternidad, desde el momento en el que él es Padre, la segunda potencia se presenta a él como el Hijo por venir, él tiene, pues, ya en ella al Hijo futuro, él le conoce previamente en ella, y es solamente en él como, propiamente hablando, él forma el designio del mundo" (Ibid., p. 332).
} 
perpetuamente "actual" que define en primer término al Absoluto. Por emplear las categorías modales tradicionales, podría legítimamente decirse que la raíz última de la "realidad necesaria" de Dios se situaria, pues, en la "posibilidad" que este alberga de dar lugar al surgimiento en su seno de potencias pertenecientes a un ser aún no existente. Es gracias a ello como Dios es verdaderamente "espiritu viviente": siendo ya actualmente "aquel que será"39.

Más aun: el rasgo de negatividad y contingencia que ahora se aloja en el núcleo mismo de lo absoluto resulta acentuado cuando Schelling postula que la posibilidad de lo "otro" y "múltiple" surge en el "espíritu perfecto" solamente "como lo imprevisto (Unversehene), lo no-premeditado (Unvorhergesehene) y, por así decirlo, lo inesperado (Unerwartete)" 40 . La posibilidad de lo "otro" emerge en el interior del Absoluto en cierto modo contra la propia voluntad de este, con independencia de que haya sido o no expresamente deseado: a modo de un huésped no expresamente invitado que, sin embargo, irrumpe repentinamente en la consciencia divina desde las profundidades de su más intima interioridad. No obstante, tal irrupción no conscientemente buscada, lejos de constituir una imposición "penosa" para el espíritu absoluto, supone realmente el fundamento de la libertad de su voluntad. Esta aparente paradoja en virtud de la cual la capacidad real de libre decisión por parte de Dios depende del surgimiento en su conciencia de una posibilidad indeseada e imprevista incluso por él mismo, se resuelve cuando la cuestión es considerada desde la perspectiva del puro Ser imprepensable en el cual también el propio espíritu absoluto "es". En efecto, la aparición de tal posibilidad sitúa al Absoluto ante la representación potencial de aquello que él aún no es, pero podría llegar a ser en caso de desearlo; le muestra, por tanto, un objeto contingente de su pura voluntad que esta puede aceptar (tornándolo existente y real) o rechazar (dejándolo persistir como una pura posibilidad, como un "no-ser"). Es a través de la exposición del Absoluto a esta posibilidad de aceptación o rehúso referida a un futuro modo de su propio ser, como el espíritu perfecto deviene consciente de su propia libertad, o lo que es lo mismo, de su capacidad de elección entre múltiples posibilidades.

Al hallarse situado ante la apertura de esta virtual disyuntiva, Dios se torna además, propiamente hablando, consciente de sí mismo como ser volente,

\footnotetext{
39 "El Dios que deviene y se revela en la historia, es precisamente el Dios Viviente. No podemos esperar comprender la Lebendigkeit, la 'viveza' ('vivance') o la 'vivacidad' de Dios, del cual la Escritura nos informa que es un Dios viviente, más que elucidando la posibilidad de este devenir histórico de y en Dios mismo" (Courtine, J.-F., Schelling entre temps et éternité...., p. 48).

${ }^{40}$ SW, v. XIII, p. 267.
} 
toma conciencia de si en cuanto voluntad, y este descubrimiento de su capacidad para querer constituye el germen de la posible emancipación del Absoluto con respecto al Ser originario que constituye el fondo oscuro e indeterminado de toda existencia: "esta aparición de la primera posibilidad de un ser diferente (verschiedenen) de sí mismo, le sitúa por primera vez en libertad frente a la necesidad de su Ser imprepensable (Unvordenklichen Seyns)"41. El surgimiento de esta posible segmentación del espíritu absoluto en múltiples potencias es la raíz de la "ruptura de la absoluteidad" de Dios de la que Schelling hablaba en Philosophie und Religion. Asimismo, esta ruptura es también la fuente de la cual procede el "salto" (Sprung) por el que era postulada la eclosión de la realidad finita: "Todo producto es, pues, la obra común de las tres potencias, que... se comportan como potencias demiúrgicas, cósmicas, cuya colaboración (Zusammenwirkung) da nacimiento primeramente a todo aquello que es concreto"42.

Cuando Schelling alude al Unvordenkliche Seyn, al Ser refractario a la reflexión y al pensar discursivo, se refiere al puro hecho de la existencia desnuda, al simple quod, al "Ser o existir incondicionado que vemos propiamente al comienzo", en el cual "aquello que en él es del orden del quid nos permanece aún oculto"43. Ahora bien, al contrario que en el caso de la teología tradicional, este Ser primigenio precede al propio Dios y se "impone" a él. Dios no es totalmente un ens a se, no se ha dado a sí mismo el ser (aseidad) de forma "voluntaria" ni este deriva directamente de su concepto, como aún sostenía Schelling en

\footnotetext{
41 Ibid., p. 268.

42 Ibid., p. 289.

${ }^{43} \mathrm{SW}, \mathrm{v} . \mathrm{XIV}$, p. 337. Se trata de la misma intuición del factum brutum de la simple existencia al cual se refería Schelling en sus Aphorismen über die Naturphilosophie de 1806 en los siguientes términos: "A cualquiera que lo considerase haciendo abstracción de su especie y su forma, el simple existir (Daseyn) debería aparecérsele como un milagro y colmar el alma de asombro, del mismo modo que es indudablemente esta experiencia del puro existir (Bemerkung des reinen Daseyns) la que, en los presentimientos más antiguos, llena las almas de pánico y de una suerte de terror sagrado (heiligem Schrecken)" (SW, VII, p. 198). En el Freiheitsschrift de 1809 se refiere, asimismo, a este trasfondo abismático de lo real caracterizándolo como "la inasible base de la realidad de las cosas (Dieses ist an den Dingen die unergreifliche Basis der Realität), el resto que nunca se puede reducir, aquello que ni con el mayor esfuerzo se deja resolver (auflösen) en el entendimiento, sino que permanece en el fundamento" (SW, v. VII, pp. 359-360). J.-F. Marquet, en su clásica monografia sobre Schelling, observa al respecto: “¿Qué es la existencia en tanto que la consideramos para sí, sin ponerla explicitamente como existencia de un sujeto propio?... Si permanecemos ahí no tenemos ninguna diferenciación entre los seres, no obtendremos más que un fundamento él mismo indeterminado para aquello que hay de más general en las cosas: la existencia... Y es solamente, se puede decir, porque Dios (o más bien aquí, la naturaleza) tempera sin cesar su existencia, por lo que se puede encontrar en las cosas claridad, acuerdo y consistencia; del mismo modo en que el dulce reino de los olímpicos no existe más que rechazando el caos y lo informe, las prodigiosas generaciones de las primeras épocas" (Marquet, J.-F., Liberté et existence. Étude sur la formation de la philosophie de Schelling, París: Gallimard, 1973, pp. 333-334).
} 
el "período de la filosofía de la identidad"44, sino que -en este sentido generalpertenece necesariamente a él o existe en él al mismo título que el resto de los entes ${ }^{45}$. Puesto que Dios "no se encuentra libre o voluntariamente" en el Ser ni en su propio modo de existir, el surgimiento de una posible alteridad en su interior "lo libera de esta Anánkē, ciertamente sagrada y sobrenatural, pero inquebrantable (unverbrüchlichen), en brazos de la cual él ha sido, por así decirlo, concebido desde el principio, y en la cual había reposado hasta ese momento"46. El heiligem Schrecken o "pánico sagrado" que, según los Aphorismen de 1806, experimenta la conciencia finita ante la exposición al puro hecho de la existencia sin existentes concretos (ante la igualmente sagrada Anánkē del Ser), se transmuta, en el caso del espíritu absoluto, en liberación con respecto a la férrea necesidad que también sobre él ejercía el desnudo Ser imprepensable.

Sin embargo, la posibilidad de esta contingencia emerge en el seno del Absoluto de forma imprevista e involuntaria, es decir, le resulta, en cierto modo, tan inexorablemente "impuesta" como lo era anteriormente la propia necesidad de su existencia de la cual aquella habría venido a liberarle. De hecho, según Schelling, el sustrato subyacente a todo el proceso de "potencialización" y segmentación del Absoluto continúa siendo, de modo inevitable, ese "Ser" primigenio, indeterminado y oscuro que precede radicalmente (a título de presupuesto originario de todo existente concreto) incluso al Absoluto mismo y a la razón ${ }^{47}$. Schelling describe este puro "Ser ciego" (blind Seyende) e irreductible

\footnotetext{
44 A título ilustrativo, compárese esta doctrina tardia schellingniana con la concepción "identitaria" entre Ser y Absoluto de la cual hacía gala su pensamiento en torno a 1804: "Si el ser no se derivase inmediatamente de la idea de Dios, es decir, si su idea no fuera ella misma la de la realidad absoluta, infinita, entonces él estaria determinado por algo que no es su idea, es decir, se hallaría condicionado por algo distinto (Verschiedenes) de su concepto, por lo cual sería en general dependiente (abhängig), no absoluto" (Schelling, F.W.J., "Philosophie der Kunst", en: SW, v. V, pp. 373-374).

45 Jean-Luc Marion se refiere a esta pertenencia de Dios al Ser, en cuanto él también es un ente, del siguiente modo: “Toda posibilidad no metafisica de 'Dios' se encuentra gobernada de entrada por la tesis (¿por la hipótesis, la hipoteca?) del Ser que lo acogerá solo como un ente. Si hay 'Dios' fuera de la metafísica, este solo podría ser si es a título de ente desplegado en su ser y, por tanto, según el Ser. El Ser ofrece de antemano la pantalla en la que se proyectaría y aparecería todo 'Dios' que quisiera constituirse ya que, por definición, constituirse significa constituirse como ente. ¿Se trata, pues, de constituirse como ente de/en el Ser, tal como uno se constituye prisionero, literalmente 'el prisionero divino' del Ser?” (Marion, J.-L., Dios sin el ser, Barreto, J. y otros (trads.) : Ellago Ediciones, 2010, p. 110).

${ }^{46}$ SW, v. XIII, p. 268.

47 Ya Kant se había apercibido de esta radical prioridad del puro Ser sobre la existencia necesaria del propio Dios, así como de su absoluta irreductibilidad a la razón fundamentada sobre el principium rationis y sus demandas de fundamento. Así, en un sentido muy próximo a lo expuesto por la Philosophie der Offenbarung schellingniana, escribe: "La incondicionada necesidad que precisamos de modo tan indispensable como último apoyo de todas las cosas, es el verdadero abismo
} 
al pensamiento parangonándolo con el fenómeno del puro deseo, de la voluntad incondicionada: "también este ser ciego que constituye el comienzo, que es el

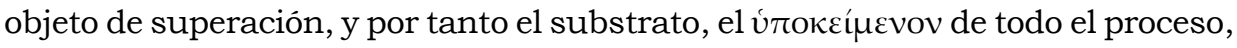
es aún en sí mismo un elemento puramente espiritual, igual que en nosotros una voluntad decidida, inflamada, es todavía algo espiritual. Debemos observar, asimismo, que esta voluntad, en su puro ser-inflamado (Entbranntseyn), allí donde ella no es aún atemperada ni afectada por otra voluntad, se muestra como aquello que es contrario a todo lo concreto. Es solo a través de su relación con otra voluntad como reviste progresivamente cualidades materiales" 48 .

Así pues, el simple Ser separado de todo ente concreto y definido subyace permanentemente a título de fundamento -o más bien de "in-fundamento" (Un-grund) - bajo la totalidad del proceso de desarrollo sucesivo que conduce al Absoluto hacia su autoconciencia como ser efectivamente volente y libre. Con ello recalamos en el rasgo esencial que determina la totalidad de la Bildungsroman del Absoluto. Esta radical antecedencia del Ser con respecto a la existencia concreta misma del ente divino implica que este se encuentra velis nolis perpetuamente colocado ante un abismo ontológico; expuesto a la inaprehensible necesidad representada por un Ser indeterminado y oscuro "anterior" y "superior" a él, del cual él mismo "participa" en calidad de "ente" (de "algo que es") 49 . Incluso el espíritu perfecto y absoluto es oscuramente consciente de esa remisión suya al puro abismo sin fundamento (Ab-grund) representado por el "Ser imprepensable": un existir abismático que fagocita por esencia toda tentativa de justificación o racionalización proveniente del recurso

\footnotetext{
para la razón humana... No podemos ni evitar ni soportar el pensamiento de que un ser que nos representamos como el supremo entre todos los posibles, se diga a sí mismo en cierto modo: Existo de eternidad a eternidad; nada hay fuera de mí, excepto lo que es algo por voluntad mía, pero ¿de dónde procedo yo?... Aquí se hunde todo bajo nuestros pies (sinkt alles unter uns); tanto la mayor perfección como la más pequeña, flota sin fundamento (Haltung) alguno ante la razón especulativa.... Aunque la cosa misma esté dada, no es comprendida (obzwar die Sache selbst übrigens gegeben, aber nur nicht eingesehen ist)" (Kant, I., Kritik der reinen Vernunft, A 613-614). 48 SW, v. XIII, p. 289.

49 Schelling explicita con meridiana claridad esta decisiva idea al comienzo de la segunda lección de Der Monotheismus. Merece la pena citar integramente este pasaje fundamental: "Del mismo modo, si hay algo fuera de Dios (ausser Gott), esta otra cosa tiene en común con él el Ser, es decir, que ella es al mismo título que Dios es. Si no puede haber nada distinto de Dios, entonces Dios no puede ser él mismo un ser (Seyn), un ser tal que participaría solo en el Ser (como, por ejemplo, aquello que es blanco rojo o bello no hace sino participar de lo rojo, lo blanco o lo bello, sin ser ni lo blanco mismo, ni lo rojo mismo ni lo bello mismo). Si Dios no es un ser, un simple participante en el Ser, no le queda sino ser el Ente mismo (das Seyende selbst), ipsum Ens" (SW, v. XII, pp. 24-25). Ya hemos observado cuáles son las aporias a las cuales conduce esta última posibilidad desde la perspectiva de la propia filosofia schellingniana del Absoluto.
} 
al Satz von Grund, a la pregunta relativa al porqué50. En referencia al simple

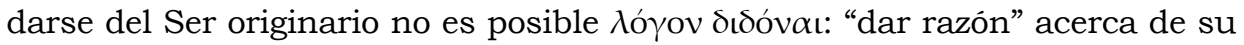
insoslayable presencia "antes de" y "en torno a" todo existente determinado, incluido el propio espíritu absoluto. Más aun: la posibilidad de emanciparse de ese "abismo de la razón" (siguiendo la expresión de Kant), que es el puro existir incondicionado abierto por la virtual -es decir, voluntaria-capacidad de Dios para actualizar en sí algo diferente de sí mismo, lo hace inmediatamente recaer en el "abismo de la libertad" resultante de esa misma posibilidad de optar libremente entre opciones diversas.

Por tanto, la existencia misma del Absoluto bascula de forma permanente entre dos abismos: o bien Dios resulta constreñido por su participación (en cuanto "ente existente") en el puro Ser imprepensable y neutro que lo precede y determina, o bien su liberación con respecto a la necesidad impuesta por tal Ser implica la caída en el abismo de la libertad en el cual ingresa al emanciparse del abismo ontológico anterior ${ }^{51}$. Un abismo de la libertad que el propio Schelling había caracterizado desde un punto de vista metafísico como "libertad de decisión entre el bien y el mal" en el Freiheitsschrift de 1809. La apertura de este espacio de oscilación en el cual se mueve ahora la conciencia absoluta constituye la genuina raigambre de su proceso de autoconocimiento merced al periplo a través de la alteridad que hemos venido designando mediante la fórmula "Bildungsroman del espíritu": su verdadero punto de origen, así como su única razón de ser. Schelling da cumplida cuenta de esta intuición fundamental cuando, en las Stuttgarter Privatvorlesungen de 1810, declara: "Todo ser viviente comienza por la ausencia de consciencia, por un estado en el cual todo está aún inseparablemente recogido (ungetrennt beisammen) que después evolucionará singularmente a

\footnotetext{
50 "Manifiestamente, Dios no es ente (seyend) desde la eternidad, hay algo que precede al Dios ente, a saber: un estado caótico y lleno de contradicciones (chaotischer widerspruchsvoller Zustand) propio de una naturaleza anterior, que debe ser primeramente atemperado (besänftigt) y puesto como pasado, antes de que Dios exista de modo efectivo (wirklich da ist)" (Schelling, F.W.J., Weltalter-Fragmente, Stuttgart-Bad Cannstatt: Fromman-Holzboog, 2002, pp. 226-227).

51 Jürgen Habermas, a su peculiar modo, da cuenta de la oscilación en la cual desemboca la "filosofia positiva" cuando escribe: "solo por medio de una decisión ya no justificable teóricamente, podrian ser reducidas de nuevo todas las determinaciones lógicas tomadas conjuntamente a un ser de todos los seres, el cual tiene fuera de sí a la existencia como lo absolutamente impensable. Pues, o bien la relación de ser y existencia es pensada en la filosofia negativa de nuevo en cada estadio de la actualización y despotencialización y, entonces, la existencia no puede proclamarse con seriedad como lo impensable, o bien la relación de ser y existencia se ha retirado efectivamente al pensar; entonces la filosofia negativa es superflua en su totalidad" (Habermas, J., "Idealismo dialéctico en tránsito al materialismo. Consecuencias filosófico-históricas de las ideas de Schelling de una contracción de Dios", en: Teoría y praxis, Mas, S. y C. Moya (trads.), Madrid: Tecnos, 1990, p. 203).
} 
partir de él; no hay ahí todavía en absoluto conciencia con escisión (Scheidung) y diferenciación (Unterscheidung). Es de esta misma forma como comienza la vida divina. Esta contiene todo en sí misma, es una plenitud infinita... en estado de total no-división (Ungeschiedenheit). Dios no existe ahí más que como silenciosa reflexión sobre sí mismo: sin exteriorización ni revelación alguna. Tal es el estado que hemos caracterizado como indiferencia (Gleichgültigkeit) de las 'potencias'... Por anticipación, podemos decir ahora que todo el proceso de la creación del mundo, el cual se extiende en forma de proceso vital a la naturaleza y a la historia, no es propiamente otra cosa sino el proceso consumado del hacerse-consciente (Bewusstwerdung), de la perfecta personalización de Dios"52.

Igualmente, al final de su producción teórica, en el marco de las lecciones sobre Philosophie der Offenbarung, el pensador de Leonberg narra nuevamente la Bildungsroman del espíritu absoluto, su odisea en pos de la Selbstbewusstsein (autoconciencia), en términos que evocan de modo expreso la estructura del paralelo periplo cognoscitivo llevado a cabo por la conciencia finita: "Pero aquello que está fuera de sí mismo (Aussersichseyende) y que es reconducido a sí mismo, es también por ello aquello que ha encontrado acceso a sí mismo, aquello que ha devenido consciente de sí mismo. Y aunque el verdadero momento de este acceso-a-sí-mismo ( $\mathrm{Zu}$-sich-selbst-kommens) es solamente el fin del proceso, o adviene solo al final del proceso, podemos, no obstante, decir: el proceso en su totalidad no es más que un venir-a-sí-mismo sucesivo de aquello que en el hombre... es consciente de sí mismo. Esta conciencia final de sí-mismo debía por tanto tener conciencia de todo el camino entero, de todos sus momentos, y, por decirlo así, de todas las alegrias y sufrimientos de esta restitución (aller Leiden und Freuden dieser Widerbringung)" 53 . La posibilidad de autoconciencia real por parte de Dios se paga, pues, al precio de encontrarse expuesto a un abismo diferente de aquel representado por la existencia desnuda e imprepensable: un abismo no ya solamente ontológico, sino -en cierto sentido peculiar- también "moral". La Bildungsroman recorrida por la consciencia finita del hombre incluye también, de modo equivalente, esta doble remisión a lo abismático: la encarnada por la captación originaria y preontológica del puro Ser, y la derivada de las posibles decisiones de orden "ético" que tal percepción ocasiona inevitablemente. A la elucidación del sentido de esta segunda "novela de formación" paralela a la del Absoluto, pero protagonizada en esta ocasión por la conciencia humana, dedicaremos el último apartado de la investigación.

\footnotetext{
52 SW, v. VII, p. 432-433.

53 SW, v. XIII, p. 287. 


\section{Entre el Ser y los entes: la inmóvil odisea de la conciencia finita}

En cuanto ser finito y contingente, el hombre se encuentra ya desde el comienzo abocado al abismo de la libertad. La posibilidad de decisión entre opciones varias pertenece constitutivamente a su naturaleza aún no totalmente configurada, a su "esencia en devenir". Esta libertad, entendida al modo en que lo hace Franz Rosenzweig kantianamente como "milagro en el mundo del fenómeno" 54 , vendría a coincidir con el espontáneo "milagro" representado por la emergencia de la posibilidad de elección voluntaria en el seno del "noúmeno supremo", esto es, en la conciencia del espíritu absoluto. Ahora bien, al igual que le sucede a esta en su relación con el unvordenkliche Seyn, también la apertura de la consciencia humana hacia la exterioridad remite, en último término, a un Ser indeterminado e inaprehensible mediante la reflexión que subyace de modo permanente a todo elemento mundano concreto y definido (a todo "ente"). Situada en un punto equidistante entre el Ser que posibilita la aparición de los entes determinados y estos mismos "objetos" con los cuales ha de tratar cotidianamente, la conciencia finita repite a su modo la peripecia del Absoluto, si bien "a escala reducida" y de un modo que no implica realmente tránsito o proceso sino en un peculiar sentido. A tal respecto, podría aplicársele con toda justicia a la captación humana del Ser aquella disposición que Schelling prescribe a la hora de considerar racionalmente el "ser en sí" del propio Absoluto, esto es, el momento inicial en el que aún no es consciente de sí mismo: "toda comprensión consiste en un hacerse-a-sí-mismo-objetivo (sich-gegenständlichMachen), pero aquí se trata de pensar lo absolutamente no-objetivo en esta no-objetividad que le es propia. Ciertamente, el hombre comprende aquello a lo cual puede aún acceder a través de un movimiento de su pensar (Bewegung seines Denkens), pero este primer concepto no es comprendido y efectivamente pensado más que en el no-movimiento (Nicht-Bewegung) precisamente"55. Así pues, la Bildungsroman propia del espíritu finito se muestra como un paradójico "periplo inmóvil" que acontece solamente en el marco de la relación que la subjetividad mantiene con el puro hecho del Ser y con los entes a los cuales este acoge. Es aquí donde cabe pertinentemente incardinar las observaciones indicadas al comienzo acerca de la relación postulada por Schelling entre la intuición como "facultad del alma" y el Ser incondicionado, la cual (merced al parentesco de la subjetividad con el Absoluto) se da de forma inmediata

\footnotetext{
${ }^{54}$ Rosenzweig, F., El nuevo pensamiento, Reguera, I. (trad.), Madrid: Visor, 1989, p. 28.

55 SW, v. XIII, p. 251.
} 
a través de la intuición intelectual. A este respecto, Schelling apunta que "el entendimiento, es decir, la única potencia capaz de conceptos, no es él mismo sino el poder o la potencia de todo ser en posesión de ella misma o remitente a sí misma; potencia cuyo correlato natural es solamente el Ser en general (das Seyn überhaupt), y tal es la razón por la cual el entendimiento no ve en cada objeto particular más que esto mismo: el objeto en general"56. Así pues, el correlato último de la intuición humana sería la captación puramente inmediata del Ser al margen de los entes finitos, del mismo modo que -como vimos- al existir incondicionado del Absoluto no le convenía la demostración mediatizada por conceptos, sino que resultaba únicamente accesible mediante la pura intuición (apareciendo, por tanto, como "indemostrable" desde la perspectiva del principium rationis).

La particular Bildungsroman del espiritu humano tiene lugar, pues, en un contexto donde lo que se halla en juego es la determinación del estatus que le corresponde a la subjetividad en el espacio de su constitutiva remisión a un Ser neutro e indeterminado que la precede de forma radical. Desde este punto de vista, también el sujeto finito -como el espíritu absoluto y perfecto- se encuentra $a b$ initio expuesto a un abismo ontológico que se superpone a aquel otro abismo surgido de su naturaleza como ser capaz de libre decisión. Esta original exposición al abismo del Ser marca el inicio de una "odisea de formación" para la conciencia humana que en realidad -dado su carácter inmóvil- constituye un simple fenómeno de Anerkennung (reconocimiento), es decir, en cierto modo, un acto de anagnórisis aristotélica merced al cual la subjetividad "toma

\footnotetext{
56 Ibid., pp. 298-299. Schelling ilustra esta intuición mediante el recurso al ejemplo de la conciencia "inmediata" infantil: "¿cómo puede suceder, visto que nuestros sentidos no son nunca afectados más que por cosas particulares, un árbol particular, por ejemplo, que instintivamente y sin que tengamos conciencia de efectuar tal operación, nombremos, sin embargo, desde el principio este objeto por medio de un concepto universal, a semejanza del niño sumergido en la oscuridad que, sintiendo la presencia de un objeto que no puede nombrar, dice con el mismo impulso y sin reflexión alguna: 'hay algo' (hier ist etwas), y recorre así con una increíble rapidez toda la escala de posibles conceptos universales hasta el escalón más alto en el cual no le queda ya más que el concepto de Ser en general (Seyenden überhaupt) que es, según la antigua ontología, el summum genus, el más alto concepto genérico? Pero todo concepto universal indica una potencia de nuestro entendimiento que excede con mucho toda experiencia... y que no puede sino provenir de una potencia infinita (unendlichen Macht) que nuestro entendimiento posee" (Ibid., p. 298). En las lecciones de Múnich Zur Geschichte der neueren Philosophie (1827), se retoma este motivo en el contexto de una metacrítica de la crítica humeana a la noción de causalidad: "No tenemos necesidad de tal ficción [el Philosophus autodidactus de Abentofail] para refutar a Hume, puesto que el niño en su cuna, que no ha tenido aún la ocasión de habituarse a una sucesión determinada de fenómenos, y que menos todavía ha oído hablar de causa y efecto, si oye un ruido, se vuelve hacia la dirección (Gegend) de la cual proviene el ruido con la única intención de ver la causa del mismo: luego presupone claramente una" (SW, v. X, p. 78).
} 
conciencia" (gnôsis) de aquello que realmente ella "era" ya desde siempre (aná): de su "papel" en el seno de la pertenencia general al Ser. En este sentido, ambas Bildungsromane (las protagonizadas por el Absoluto y por la conciencia finita), difieren esencialmente. Mientras que la primera se dirige hacia una apoteosis (nunca mejor dicho) del saber, hacia un progresivamente más elevado volumen de autoconciencia e intensificación de la subjetividad (recordemos que a tal respecto hablaba Schelling de fortwährenden Steigerung), la segunda conduce, habida cuenta de sus resultados en la filosofia contemporánea, en sentido totalmente inverso. Veamos de qué modo sucede tal cosa.

En las Stuttgarter Privatvorlesungen (1810), Schelling habia postulado ya una esencial continuidad entre la "estructura" propia de las consciencias divina y humana ("Dios tiene en si los mismos principios que nosotros" ${ }^{57}$ ) que justifica plenamente nuestro modo de parangonar ambas odiseas cognoscitivas. El punto esencial de coincidencia entre espíritu finito e infinito lo constituye, según Schelling, su común disposición "estructural" en dos ámbitos o "principios": uno "superior" marcado por la plena luminosidad de la consciencia, y otro "inferior" definido por la oscuridad y la inconsciencia. En el caso del espíritu absoluto, el tránsito hacia la claridad de la consciencia desde "la noche de su esencia" (Nacht seines Wesens) original comienza con la escisión interna en múltiples potencias que -como hemos expuesto- desencadena el proceso de su Bildungsroman particular. Mientras la subjetividad divina todavía dormita sumergida en el principio oscuro, en el "silencioso meditar" (stilles Sinnen) de su contracción e inconsciencia originarias, Dios posee los dos "principios" en estado de total indiferencia, es decir, que no es aún capaz de reconocerse privilegiadamente en ninguno de ellos. La Anerkennung de sí mismo adviene solo a partir del momento en que el "despertar de la conciencia" comienza su curso, su devenir, merced a la posición sucesiva de la tríada de las potencias ${ }^{58}$.

57 SW, v. VII, p. 433. Igualmente: "Si deseamos un Dios que podamos considerar como un ser plenamente viviente (ganz lebendiges) y personal, entonces nos es necesario también considerar a Dios de forma totalmente humana (ganz menschlich), debemos admitir que su vida tiene la más grande analogía con la vida humana y que en él, al lado del ser eterno, hay también un devenir eterno (ewiges Werden). En una palabra: que lo tiene todo en común con el hombre, a excepción de la dependencia" (ibid., p. 432).

58 Ingeborg Schüssler describe el tránsito ontológico entre los dos "momentos" esenciales de la existencia del Absoluto del siguiente modo: "Para comenzar por el primer momento, el ente mismo se distingue [en Dios] del ser; es libre de él, está fuera y por encima de él: es aquello que libremente puede ser o no ser; es, pues, el poder de ser o de no ser... En efecto, si Dios, en su primer momento, no es sino puro poder de ser -sin ser del todo-, entonces es necesario que él sea, en su segundo momento, puro ser, sin poder de ser. Del mismo modo, pues, que Dios, en su primer momento, no es más que puro poder de ser, sin ser, vale decir: puro subjectum, que como tal - 
Es entonces cuando "lo más alto (Höhere) en Dios rechaza, por así decirlo, a lo más bajo (Niederere) con lo cual se encontraba hasta entonces en indiferencia y mezcla, y a la inversa: lo más bajo se disocia en él mismo de lo más alto por su contracción", y ello constituye, "tanto en el hombre como en Dios, el comienzo de su consciencia, de su personalización (Persönlichwedens)"59.

Ahora bien, en el caso de la subjetividad finita, ese principio oscuro e inconsciente que es necesario subordinar a la claridad del pensar reflexivo guarda una esencial relación con la referencia "instintiva" al puro Ser que Schelling había ya detectado en la espontaneidad propia de la consciencia infantil. En efecto, la simple percepción del "hay" en general -en el sentido levinasiano del término-60 era descrita por Schelling en sus lecciones muniquesas de 1827 como una operación efectuada de modo puramente instintivo (instinktmässig) y carente de conciencia: "sin reflexión alguna". Esta "infinita potencia de nuestro entendimiento", como él la denomina, entronca, pues, plenamente con el "principio oscuro" existente en nosotros, puesto que el correlato de una facultad infinita debe constituirlo un "referente objetivo" igualmente infinito (esto es,

como fundamento y poder de ser- permanece en estado de latencia, que no se manifiesta, no se exterioriza ni se objetiva, del mismo modo Dios, en su segundo momento, no es más que puro ser, sin poder de ser, sin subjetividad; un ser, pues, que no es sino manifestación, exteriorización: pura objetividad... Ahora bien, una cosa que por su esencia es una, pero que, como tal, no puede actualizarse más que por la superación de una separación actual, no puede actualizarse sino progresivamente, a través de un proceso" (Schüssler, I., "La mythologie comme processus de la conscience dans la Philosophie de la mythologie de Schelling”, en: Courtine, J.-F. y J.-F. Marquet (eds.), Le dernier Schelling..., pp. 136-139). Sobre esta retracción latente de Dios que deviene con posterioridad exteriorización, el propio Schelling indica que, en consonancia con la conocida práctica ritual de los brahmanes hindúes al contener el ritmo de la respiración, "aquello que en la Deidad (Gottheit) es más profundo, lo más intimo y, digámoslo así, lo más encerrado en sí mismo (Abgeschiedensten), no será, de hecho, experimentado (empfunden) en una expansión o una expiración, sino que será encontrado y experimentado solamente en la más elevada atracción (retracción) y, por así decirlo, como una inspiración absoluta del pensamiento" (SW, v. XIII, pp. 251-252).

59 SW, v. VII, p. 434.

${ }^{60}$ En su obra de 1947, Emmanuel Levinas describe la neutralidad y el anonimato propios del simple "hay" (il y a) que subraya su presencia en el insomnio, del siguiente modo: "La imposibilidad de desgarrar lo invasivo, el inevitable y anónimo murmullo de la existencia, se manifiesta en particular a través de ciertos momentos en los que el sueño se sustrae a nuestras llamadas. Se vela cuando no hay ya nada que velar y a pesar de la ausencia de toda razón para velar. El hecho desnudo de la presencia oprime: se está apegado al ser (tenu à l'être), apegado a ser. Se desliga uno de todo objeto, de todo contenido, pero hay presencia. Esta presencia que surge detrás de la nada no es ni un ser ni el funcionamiento de la conciencia ejerciéndose en vacío, sino el hecho universal del hay, que engloba a las cosas y a la conciencia" (Levinas, E., De l'existence à l'existant, París: Vrin, 1990, p. 109). Sobre las posibles relaciones entre Schelling y Levinas en referencia a esta cuestión, véase: Steinkamp, F., "Eternity and Time, Levinas returns to Schelling", en: Wirth, J.M. (ed.), Schelling now. Contemporary Readings, Indiana: Indiana University Press, 2005, pp. 207-222. 
indeterminado y simple), este no puede ser sino el "concepto general de Ser". Injertada la cuestión en un contexto estrictamente perceptivo o "empírico" (que es, por lo demás, como la aborda Schelling al caracterizar el comportamiento de la conciencia infantil sumergida en la oscuridad), el principio "elevado" y "luminoso" en el hombre se identifica con su percepción consciente de entes determinados, mientras que el principio oscuro extraño a la reflexión lo hace con la simple intuición inmediata del Ser en general. Esta última aparece, así, como un acto de mera captación irreflexiva ("instintiva", diria Schelling) situada al margen de toda consciencia y de toda racionalidad discursiva mediatizada por conceptos, es decir, ajena a todo aquello que representa propiamente la subjetividad racional stricto sensu.

De este modo, a la vez que la Bildungsroman emprendida por la conciencia absoluta conduce a esta hacia cuotas cada vez más elevadas de consciencia de sí, la paralela odisea experimentada por el sujeto finito situado ante su particular abismo ontológico parece orientarse en una dirección totalmente inversa. La crónica de esta deriva hacia el ocaso de la subjetividad del hombre comienza acaso en la Spätphilosophie schellingniana y prosigue con la demoledora critica de Nietzsche a la noción misma de sujeto "autofundado", para consumarse definitivamente en el marco de la crítica a la moderna "metafísica de la subjetividad" elaborada por el discipulo encubierto del último Schelling que es Heidegger ${ }^{61}$. La abolición del sujeto decretada en el contexto del pensamiento hermenéutico posmoderno o en la noción foucaultiana de "muerte del hombre" no constituye, contemplada desde este prisma, sino el consecuente epílogo de tal crónica. En particular, el concepto heideggeriano de "historia del Ser" implica, en lo esencial, la sustitución del "sujeto" como protagonista preeminente del devenir temporal a favor del Ser que, como hemos mostrado, aparecía como correlato "natural" de su percepción e intuición originarias ${ }^{62}$. En el marco de la

${ }^{61}$ En referencia al fenómeno de automediación de la razón en el último Schelling del que habla Walter Schulz, Habermas esboza el proceso de "superación" de la subjetividad que surge a partir de aquel, en términos sensiblemente diferentes a los aquí expuestos: "La superación 'existencialista' del idealismo está preparada por Schelling, superación que, pasando por Kierkegaard y Rosenkranz, fue consumada finalmente por Heidegger. Solo este tiene éxito en aquello que Schelling cree haber alcanzado por medio del fraccionamiento del sistema: el ajuste de la problemática ontológica con la necesidad práctica de una inversión de la corrompida edad del mundo. Ambas intenciones... son forzadas conjuntamente por el hecho de que la razón se deja mediar por lo percibido, el pensar por lo que se añade, con el pensamiento a lo percibido, ya sea querigmática, ya sea mitopoiética o, por lo menos, topológicamente" (Habermas, J., "Consecuencias filosóficohistóricas.", p. 203.

62 En este sentido, Heidegger -en un tratado inédito redactado entre los años 1938 y $1940-$ apunta explícitamente lo siguiente: "La meditación permanece aún en el peligro de ser recibida 
polaridad indicada por Schelling entre la conciencia y el puro hecho del Ser, el destino de la subjetividad absoluta se orienta hacia la espiral progresivamente ascendente del autoconocimiento; el que le corresponde a la subjetividad finita apunta más bien hacia su paulatina disolución. Al final del ciclo marcado por su sedentaria Bildugsroman, el sujeto finito se reconoce -al contrario de lo sucedido en el caso de la Anerkennung del Absoluto- como instancia abocada al ocaso.

Tal vez es necesario ser Dios para situarse ante el abismo del puro Ser incondicionado y lograr sostener conscientemente la mirada en su dirección. Para la conciencia no-absoluta, esta exposición supone, o bien permanecer en la inconsciencia del "principio oscuro" (es decir, en la irracionalidad y la "ausencia de entendimiento"), o bien renunciar a la captación perentoria y "presente" del Ser, a favor de su indirecta rememoración, de su permanente anámnēsis. Es a esto a lo que, presumiblemente, se refiere Schelling en un decisivo pasaje de su Philosophie der Offenbarung, cuando caracteriza al puro "Ser-voluntad" en los siguientes términos: "es el prius de la naturaleza, aquello que precede (Vorausgehende), el rostro (como dicen los orientales), la cara del creador que, como Dios dice en el Antiguo Testamento, ningún hombre puede ver y vivir, precisamente porque es aquello que en su Ser consume todo aquello que es concreto, y que por tanto debe necesariamente ser transformado en pasado para ser soportable (erträglich) a la criatura, no deviniendo así primeramente visible más que cuando se ha convertido verdaderamente en invisible, a saber: cuando se ha revestido de la forma creatural (der creatürlichen Form überkleidet), y asî oculto por esta forma, ha devenido invisible gracias a ella"63. "Revestirse de la forma creatural" significa para el simple Ser, conforme a nuestra interpretación, aparecer "corporeizado" en un ente: no mostrarse a la intuición en su pura desnudez indeterminada intolerable para la consciencia, sino solo como Ser... del ente, como existencia encarnada en objetos finitos y determinados. Únicamente oculto bajo este ropaje mundano resulta el Unverdenkliche Seyn soportable para el hombre.

El espíritu finito precisa esencialmente de lo finito y "substancial": el rostro de la Gorgona representado por la simplicidad del Ser solamente le resulta perceptible y tolerable de soslayo: como reflejo indirecto, como huella:

como una 'ética existencial' o algo semejante, contrarrestando de ese modo aquello que la historia del Ser se propone en el futuro: la desaparición del hombre (Verschwindung des Menschen), del animal rationale y de la subjetividad" (Heidegger, M., Die Geschichte des Seyns, GA, v. LXIX, Fráncfort d.M: Vittorio Klostermann, 1998, p. 30).

${ }^{63}$ SW, v. XIII, pp. 289-290. 
"Nos representamos con inmediatez una impresión recibida de un objeto en el espacio. El primer contenido de esta representación es solamente la existencia de algo en general; qué es lo que representamos, es decir, su quid, llega solamente en un segundo momento (ist erst das Zweite). El quod [esto es, el puro Ser] es, pues, anterior (vor) al quid en la representación (Vor-stellung), la cual quizá toma de ahí su nombre... El contenido de la representación pura es el Ser (Seyn), el del puro pensamiento la esencia (Wesen). Pero enseguida se ve que ambos no pueden mantenerse en esta abstracción y exclusión reciproca (gegenseitigen Ausschliessung), y que uno pasa inmediatamente al otro... Pero ahora, frente el 'puro que' (reine Dass), el pensar se eleva inmediatamente y demanda el 'qué' (Was) o el concepto" ${ }^{64}$. De esta remisión al tranquilizador ámbito de las cosas definidas y aprehensibles conceptualmente, esto es, del volverse de espaldas al Ser, depende, pues, la "seguridad existencial" del sujeto finito ${ }^{65}$. Además, como sucedía en el caso del Absoluto, tampoco la exposición al "Ser imprepensable" es un acto voluntario o libre por parte de la conciencia finita: también se impone al hombre la insoslayable prioridad del Ser con respecto a su propia conciencia: su total facticidad.

No obstante, en oposición a lo que sucede -como se apuntó- en el singular caso del espíritu perfecto, esta imposición necesaria no representa paradójicamente el fundamento mismo de la libertad, sino justamente todo lo contrario. La peculiar "ética metafisica" schellingniana (sorprendentemente

\footnotetext{
${ }^{64}$ Schelling, F.W.J., "Einleitung in die Philosophie der Offenbarung oder Begründung der positiven Philosophie", en: SW, v. XIII, p. 173. En uno de sus últimos ensayos, Schelling apunta un rasgo esencial propio del Ser que ilumina, en cierto modo, la causa por la cual la conciencia finita necesita, en última instancia, vivir en la pluralidad de lo "óntico" y definido: "El qué (Was) conduce por si mismo a la dispersión (Weite), a la pluralidad, y por tanto también, naturalmente, a la poliarquía (Vielherrschaft), pues el qué es en cada cosa distinto, mientras que el que (Dass) es uno según su naturaleza, y por consiguiente en todas las cosas” (Schelling, F.W.J., "Abhandlung über die Quelle der ewigen Wahrheiten", en: SW, v. XI, p. 590).

${ }^{65}$ Incluso el propio Heidegger -máximo baluarte de la actitud opuesta- parece intuir, en puntuales pasajes diseminados a lo largo de su obra, este carácter potencialmente deletéreo del Ser para la intuición humana. Así, en el seminario del semestre de invierno de 1941-42, declara: "El hombre tiene su hogar (su procedencia) en esta referencia [al "claro" del Ser], pero no se siente en ella como en su casa. Ella es desapacible y, por tanto, siniestra. $\Delta \varepsilon \iota v o ́ v$. Lo tremendo, lo no de aquí ni de ahora, y lo desapacible y siniestro. El hombre y la diferencia del Ser" (Heidegger, M., Ejercitación en el pensamiento filosófico, Ciria, A. (trad.), Barcelona: Herder, 2011, p. 72). Igualmente, en su curso del semestre de invierno de 1923-1924, Heidegger, en referencia al desplazamiento de lo verum hacia lo certum en la epistemología y ontologia modernas, apunta ya lo siguiente: "Este desplazamiento (Umgang) caracteriza la preocupación del conocer, el cual lleva a cabo tal desplazamiento como preocupación por la tranquilidad (Sorge der Beruhigung), pero finalmente como preocupación por la certeza, que cierra desde el principio toda posibilidad de una fundamental inseguridad del Ser (Seinsunsicherheit)" (Heidegger, M., Einführung in die phänomenologische Forschung, GA, v. XVII, Fráncfort d.M: Vittorio Klostermann, 1994, p. 226).
} 
próxima a la distinción elaborada por Heidegger entre "existencia auténtica" e "inauténtica") reconoce al sujeto finito la posibilidad de decidirse a favor de "la mejor parte de nosotros mismos" (es decir, del principio consciente), y por tanto contra el "principio oscuro". Cuando tal cosa sucede, "la consciencia comienza, sin ser aún, no obstante, conciencia plena. Toda la vida no es propiamente sino un devenir-consciente (Bewusstwerden) siempre más elevado. La mayoría se mantiene en el grado más bajo, e incluso aquellos que se esfuerzan en ello no acceden, la mayor parte del tiempo, a la claridad... siempre subsiste aún un resto oscuro (dunkler Rest)"66. Ahora bien, ¿no consistía precisamente la "potencia infinita de nuestro entendimiento" (es decir, la consciencia en sentido eminente), según el propio Schelling, en su conexión irreflexiva "instintiva" y "no-empírica" (vale decir, "inconsciente") con el puro hecho de Ser? ¿No implica esto que la opción a favor del principio consciente y "más elevado" que hay en nosotros destruye precisamente el nexo que vincula nuestra consciencia con el Ser en general, y por tanto con aquella parte de nuestro entendimiento que nos sitúa en relación con lo infinito? Inversamente, ¿no parece depender la preservación de esta "potencia infinita" y "mejor" de nuestra consciencia paradójicamente de la opción favorable a la permanencia del hombre en el principio "oscuro"?

\section{Conclusión}

He aquí la causa por la cual la apologia schellingniana del devenirconsciente progresivamente más elevado conviene al espíritu absoluto, mientras que cuando es aplicada al espíritu finito incurre en insolubles aporias y redunda, en última instancia, en el marasmo de la propia subjetividad. Tal vez la filosofia schellingniana de la revelación ha subestimado en exceso el peso de la finitud. Una finitud que consiste justamente en el hecho de que alli donde la conciencia absoluta halla su paroxismo cognoscitivo, la conciencia finita -cuya Bildungsroman se mueve formalmente en idéntica dirección que aquella- encuentra históricamente solo declive y ocaso. Aquí radica la razón última por la cual es posible avizorar tras la gesta triumphans del Absoluto una oculta y paralela epopeya protagonizada por la consciencia finita; una epopeya desprovista de los rasgos épicos que definen el desenvolvimiento cognoscitivo del Absoluto en devenir, y que se deja adivinar más bien -remedando el conocido título de Detienne y Vernant- como la crónica del despliegue de "las artimañas que la inteligencia" (finita) dispone con el fin de defenderse de ese

\footnotetext{
${ }^{66}$ SW, v. VII, p. 433.
} 
exceso de consciencia ontológica que ella -a diferencia de lo que sucede con la conciencia infinita- es incapaz de acoger y asimilar. Así pues, si la inviabilidad del acceso cognoscitivo al Absoluto "en sí mismo" por parte de la razón (dada la esencial naturaleza inmediata y aconceptual propia de lo incondicionado) forzaba a esta, en un primer momento, a asumir la necesidad de un giro o punto de inflexión conducente a la consideración temporal e histórica -es decir, "indirecta" y "mediada"- del Absoluto a través de sus huellas y expresiones en la historicidad que constituye su efectivo despliegue ${ }^{67}$, de lo que se trata ahora es del modo en el que el espíritu finito resulta capaz de tornar erträglich (soportable, llevadera) esa misma historicidad. Una vez desechada la hýbris implícita en la pretensión de conocer directamente lo absoluto, lo que ahora se impone es la necesidad de reconocerlo a través de sus expresiones indirectas temporalmente mediatizadas, las cuales resultan ser bastante más inocuas para la percepción que la pura exposición cognoscitiva a la unerträglich (intolerable) mirada de basilisco emanada del Absoluto que el espíritu finito, como se ha indicado, es incapaz de mantener y soportar.

También en este caso, "revestir de forma creatural" al flujo indeterminado y racionalmente inabarcable del tiempo histórico significa, desde la perspectiva de la conciencia finita, tornarlo huella, objeto de mera rememoración (Andenken), hacerlo devenir Denkmal (monumento), es decir, en último término, desactivar su carácter inasimilable para la razón discursiva (carácter propio de una instancia "incondicionada") mediante un acto de racionalización asimiladora que logre parangonarlo a la subjetividad. Alborea ya aquí, pues, el sendero que conduce desde la inicial posición de lo absoluto e incondicionado -como "Yo", identidad o Gott im Werden-a su suspensión y enmascaramiento a través de un determinado tipo de caracterización filosófica acerca del tiempo: una filosofia de la historia vuelta ya de espaldas a todo fundamento divino o referente inmutable de orden metafísico. La forma en que el sujeto finito hace devenir soportable su constitutiva exposición a lo incondicionado (al Ser, a lo absoluto) mantiene un esencial vínculo con la disolución de tal incondicionado en la temporalidad y la

67 Arturo Leyte expresa este "giro" fundamental del pensamiento schellingniano del siguiente modo: "Cuando Schelling, después de 1809, asume decididamente la imposibilidad misma de la razón para conocer un absoluto que siempre se le ha escapado ya, concibe su conocimiento desde otra perspectiva: si lo absoluto o Dios no es cognoscible en sí mismo en su génesis, sin embargo puede ser reconocido en la historia, que es su revelación... Y esta traducción del tiempo que lleva de su comprensión matemática en el comienzo de la Edad Moderna al tiempo histórico que anuncia la Edad Contemporánea, vuelve a ser la señal del nihilismo que la música romántica tan bien anunció" (Leyte, A., "Schelling y la música", en: Anuario Filosófico, v. XXIX, 54 (1996), pp. 122-123).

ARETÉ Revista de Filosofía, vol. XXVIII, N², 2016 / ISSN 1016-913X 
historicidad. De ahí la decisiva relevancia adquirida por la reflexión acerca de la historia en el contexto de la filosofia general del idealismo alemán. El punto de vista histórico se muestra, desde esta perspectiva hermenéutica, como auténtico órganon investido de la facultad de lenificar y atemperar la potencia disolutiva de lo Unbedingte, y, por tanto, de garantizar soteriológicamente la "soportabilidad" de su percepción por parte de la subjetividad finita. Esta garantía de tolerancia se paga, sin embargo, al precio de abrir la hasta entonces clausurada puerta del nihilismo. Los hitos que jalonan el itinerario marcado por esta progresiva disolución de lo incondicionado y absoluto en el flujo temporal de la historia configuran acaso los momentos esenciales de la reflexión filosófica desde las postrimerías del siglo XIX hasta la actualidad.

\section{Bibliografia}

Augusto, R., "La evolución intelectual del último Schelling: filosofia negativa y filosofia positiva", en: Anuario filosófico, v. XLII, 96 (2009), pp. 577-600.

Beierwaltes, W., "El neoplatonismo de Schelling", en: Anuario filosófico, v. XXX, 67 (2000), pp. 395-442.

Carrasco Conde, A., La limpidez del mal. El mal y la historia en la filosofia de F.W.J. Schelling, Madrid: Plaza y Valdés, 2013.

Courtine, J.-F., Schelling entre temps et éternité. Histoire et préhistoire de la conscience, París: Vrin, 2012.

Duque, F., Historia de la Filosofia moderna. La era de la critica, Madrid: Akal, 1998.

Fuhrmans, H., "Der Gottesbegriff der Schellingsche positiven Philosophie", en: Koktanek, A.M. (ed.), Schelling-Studien. Festgabe für M. Schröter zum 85. Geburtstag, Múnich/ Viena: R. Oldenbourg, 1965, pp. 9-47.

Habermas, J., "Idealismo dialéctico en tránsito al materialismo. Consecuencias filosóficohistóricas de las ideas de Schelling de una contracción de Dios", en: Teoría y praxis, S. Mas y C. Moya (trads.), Madrid: Tecnos, 1990.

Heidegger, M., Grundprobleme der Phänomenologie, GA 24, Frankfurt d.M: Vittorio Klostermann, 1975.

Heidegger, M., Die Geschichte des Seyns, GA 69, Frankfurt d.M: Vittorio Klostermann, 1998.

Heidegger, M., Einführung in die phänomenologische Forschung, GA 17, Frankfurt d.M: Vittorio Klostermann, 1994.

Heidegger, M., Ejercitación en el pensamiento filosófico, Ciria, A. (trad.), Barcelona: Herder, 2011.

Jankélévitch, V., L'odyssée de la conscience dans la dernière philosophie de Schelling, Paris: L'Harmattan, 2005.

Kant, I., Kritik der reinen Vernunft, Köln: Könemann Verlagsgesellschaft, 1995.

Levinas, E., De l'existence à l'existant, París: Vrin, 1990. 
Leyte, A., "Schelling y la música", en: Anuario Filosófico, v. XXIX, 54 (1996), pp. 107124, pp. 122-123.

Marion, J.-L., Dios sin el ser, Barreto, D. y otros (trads.), Pontevedra: Ellago Ediciones, 2010.

Marquet, J.-F., Liberté et existence. Étude sur la formation de la philosophie de Schelling, Paris: Gallimard, 1973.

Rosenzweig, F., El nuevo pensamiento, Reguera, I (trad.), Madrid: Visor, 1989.

Serrano Marin, V., Absoluto y conciencia. Una introducción a Schelling, Madrid: Plaza y Valdés, 2008. http://dx.doi.org/10.5211/9788496780712

Schelling, F.W.J., Sämmtliche Werke, Stuttgart: Cotta, 1856-1861.

Schelling, F.W.J., Die Weltalter. Fragmente. In der Urfassungen von 1811 und 1813 (SW Nachlassband), Múnich: Beck, 1966.

Schelling, F.W.J., Weltalter-Fragmente, Stuttgart-Bad Cannstatt: Fromman-Holzboog, 2002.

Schulz, W., Die Vollendung des Deutschen Idealismus in der Spätphilosophie Schellings, Stuttgart: Kohlhammer, 1955.

Schüssler, I., "La mythologie comme processus de la conscience dans la Philosophie de la mythologie de Schelling”, en: Courtine, J.-F. y Marquet, J.-F. (eds.), Le dernier Schelling. Raison et positivité, París: Vrin, 1994, pp. 131-153.

Steinkamp, F., "Eternity and Time, Levinas returns to Schelling”, en: Wirth, J.M. (ed.), Schelling now. Contemporary Readings, Indiana: Indiana University Press, 2005, pp. 207-222.

Vetö, M., "L'unicité de Dieu selon Schelling”, en: Courtine, J.-F. y Marquet, J.-F. (eds.), Le dernier Schelling. Raison et positivité, Paris: Vrin, 1994, pp. 87-100.

Recibido: 25/08/15

Aceptado: 21/09/15 